\title{
The Analysis of the Hong Kong Education Policy "Language Proficiency Assessment for Teachers of English"
}

\author{
Hastings Chim Ho Yeung, ${ }^{1, *}$ \\ ${ }^{1}$ University of Bristol, UK \\ *Correspondence: University of Bristol, UK. E-mail: hoyeungmr@gmail.com
}

Received: November 16, 2014 Accepted: November 25, 2014 Published: December 21, 2014 doi:10.5296/ije.v6i4.6628 URL: http://dx.doi.org/10.5296/ije.v6i4.6628

\begin{abstract}
The Education policy “Language Proficiency Assessment for Teachers of English” had been controversial since its establishment in 2000, in the sense that various stakeholders including parents, students, school administrators, teachers and the general public. This essay critically analyses this education policy in the HK context by scrutinizing the prerequisite. Subsequently, how LPATE was built on policy texts and how it was construed as a solution of gradual decline of English as well as the reciprocal politics interacting with the policy were analyzed. Additionally, the institutions and actors involved in the policy process are discussed followed by the revelation of the outcomes of LPATE in both the expected and the unanticipated dimensions.
\end{abstract}

Keywords: Educational policy, LPATE, Bowe’s policy triangle 


\section{Ml Macrothink}

\section{Introduction}

English, as an official language of Hong Kong (HK), has exerted congruent influence upon the development spectrum of HK. The spectrum ranges from political text production, policy practice, and professionalism to common workplace communication and daily conversation (Coniam \& Falvey, 2001; DRAVE, 2010; Lin, 2007). Due to this prevallence and ubiquity, public concern was raised on the English proficiency of English teachers. Ineluctably, the government legitimized the required participation of all English teachers in the new official assessment, 'The Language Proficiency Assessment for Teachers of English (LPATE)' since 2000 (Berry \& McNeill, 2005). Adoption of the new policy has been unprecedentedly controversial because the failure to fulfill the assessment led to disqualification of teachers and consequently, vacancy of the teaching posts. Through the lens of this article, we can further our understanding of LPATE from its conception to implementation. The article likewise aims to shed light on the resistance from teachers and the process by which the education state, the government, twisted its policy direction to resolve the crisis. Most crucially, this article suggests how LPATE can be better enhanced towards fulfillment of its original purpose with less pressure on teachers in the Hong Kong context.

\section{LPATE framework of analysis}

We can apply the Hodgson and Spours (2007) notion of an analytical framework to dissect the deployment of LPATE, which comprises four major dimensions. With this framework, we can determine how the education policy and practices are wired together.

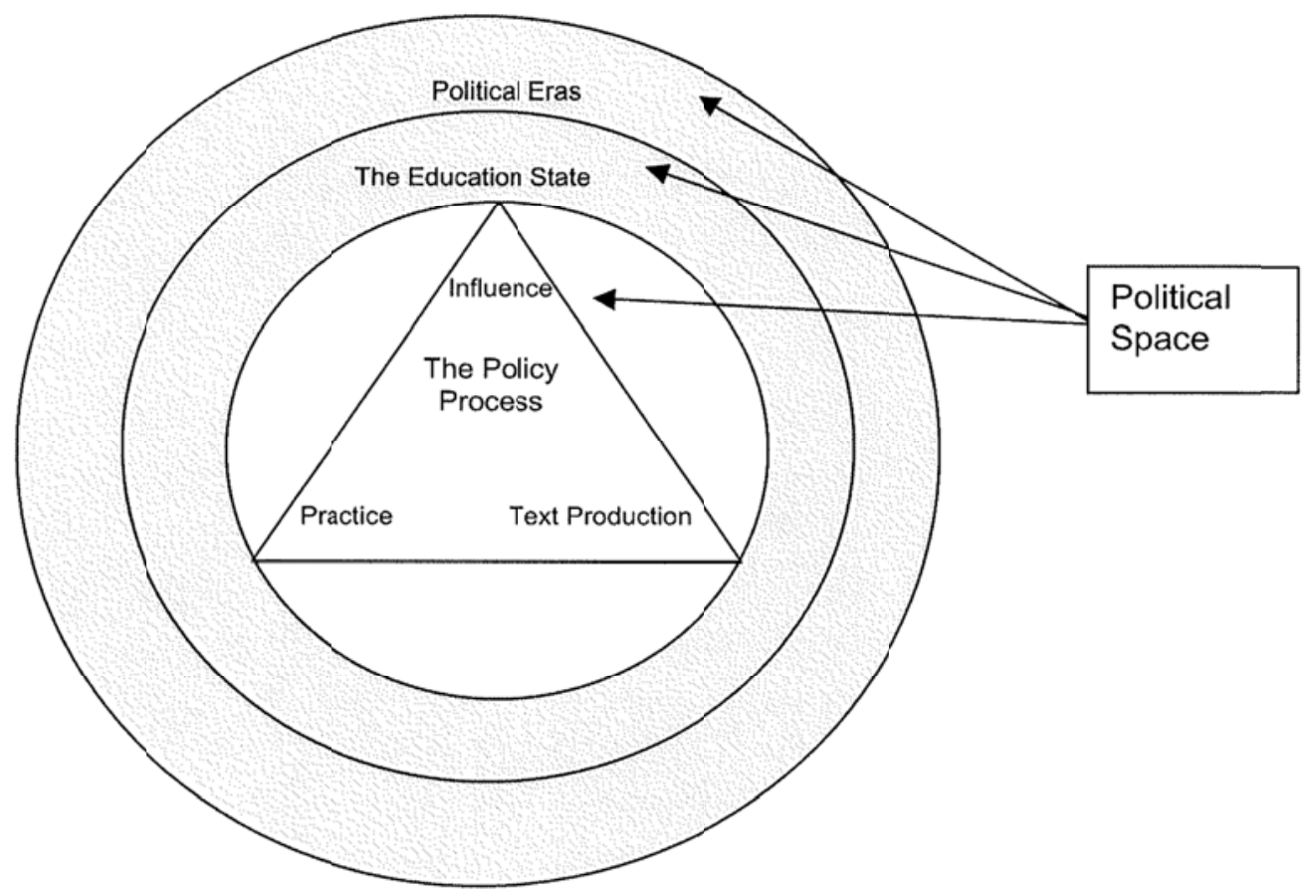

Figure 1. The rationale of the Hodgson and Spours analytical framework

The rationale of employing Hodgson and Spours as the analytical framework is valid because their article was an attempt to reflect the controversial 14-19 educational reform. To certain extent, the reform resembles the LPATE policy in the sense that 14-19 educational reform 
and LPATE policy were constructed with various policy texts and appeared in the same decade. Additionally, the framework is rooted in the concept of the policy triangle interacting with historical, political, and state contexts (Bowe et al, 1992) in which both LPATE and 14-19 reform have similarities.

\section{Expanding the toolbox for policy analysis}

The third dimension of the analytical framework of Hodgson and Spours investigates the 'dynamic and messy' nature (Bowe et al, 1992) of the entire policy-making cycle. The cycle is mainly based on the policy triangle comprising three contexts that are attributed to the formulation and implementation of the education policy. A checklist from Vidovich (2007), originally based on Bowe's policy triangle, is applied to deepen understanding of this dimension and to investigate the LPATE policy process. In the process, the questions in the list are answered to demonstrate an in-depth comprehension of the policy process.

\section{Limitations}

Nonetheless, the combined framework has limitations because the expected results from these policies are entirely different. The 14-19 Education Reform, which involved two formal consultations with educational specialists, researchers, influential individuals, and leading figures to construct the proposal was eventually disposed by the government (Hodgson and Spours, 2007). In the case of LPATE, the policy was implemented in accordance with the initial planning by the advisory committees including the Advisory Committee on Teacher Education and Qualifications (ACTEQ) and English Language Benchmark Subject Committee (ELBSC). Nonetheless, after receiving complaints from teachers, the government consented to adjusting the leveling of LPATE and providing corresponding remediation, such as full exemption, to alleviate the grievance of teachers (Lin, 2007).

\section{LPATE construction in various policy texts}

The concept of LPATE first appeared in various policy texts, which, in accordance with Hodgson and Spours (2007), did not merely refer to the reports, documents, and papers published by the government bureaus, but also to the supportive, consultative documents released by institutes, advisory committees, and professional communities.

The initial proposal can be traced back to the HK Education Commission Report No. 6 (ECR6), published in December 1995, which reflected a common consensus among businesses on the deterioration of English competence of graduates in HK. According to Coniam (1994), only one fifth of the English language teachers received professional training and held relevant English degree before engaging with the profession.

In view of the need to enhance language competency of English teachers, the government initiated in 1996 the establishment of a benchmark. The benchmark led to the proposed 
policy that could legitimize the attendance of approximately 12,500 English language teachers in both primary and secondary sectors in the assessment (Qian, 2008).

Upon this prerequisite, the Education Commission considered the significance of English in the context of the transformation of $\mathrm{HK}$ from industrial manufacturing to knowledge-condensed industries. With reference to the ECR6 report, the Advisory Committee on Teacher Education and Qualifications (ACTEQ) investigated the feasibility to incorporate "benchmark" qualifications for all English teachers in late 1996. The investigation was conducted to ensure that all teachers could meet the proficient language standard before obtaining teaching qualifications.

Presumably, the committee agreed that the candidates would not be Native English Teachers (NET) but solely Local English Teachers (LET) who received the subject training under HK mainstream education system. The second agreement involved the inclusion of the four basic competencies, namely, Reading, Writing, Listening, and Speaking, as well as a spontaneous test that could assess Classroom Language. Two standardized criteria were utilized for marking the papers: analytic scoring approach for Reading and Listening Tests and scale-based scoring approach for Writing, Speaking, and Classroom Language Assessment (DRAVE, 2010). As previously mentioned, teachers who failed would be dismissed from their current teaching posts.

Due to the high expectations posed by the assessments, it was believed that the overall assessment setting should be task-based, pragmatic, authentic, and clear. Evidently, the assumption was based on the idea that the real use of English as MOI in classroom context was being assessed, which aimed at scrutinizing the spontaneous delivery from teachers despite the fact that controlling this component was a complicated process. Moreover, the process was unprecedentedly threatening to candidates (Berry \& McNeill, 2005).

In 1999, the committee implemented the experimental stage of the benchmark by piloting the tests on selected lower secondary English teachers. The implementation aimed at determining the suitable norm and leveling of the assessments. In 2001, the examination syllabus and requirements were officially finalized and the initial official assessment was implemented three months after the publication of the syllabus.

After 2001, the assessment was implemented once between 2002 and 2003, annually in 2004 and 2005, and once a year after 2005. During the first two years, the attendance rate was low. As a result, the teachers became skeptical towards this new test. However, participation sharply rose by the end of 2006 when the government repeatedly enforced the compulsoriness of LPATE. The first phase of LPATE lasted for five years until late September, 2006. During this period, the test was amended considerably. From the attainment of the fulfilling assessment results, the objective leaned towards partial fulfillment of full exemption for teachers who have been awarded relevant degrees and have undergone specified teachers' training. 


\section{Critical analysis}

\section{Dimension 1. Political eras}

The first dimension of the framework of Hodgson and Spours indicates the political eras behind the policy, which categorically refer to historical and contextual analysis for LPATE, given that the underpinnings of this education policy should first be explored by identifying its origins. When assessing the 14-19 reform, Hodgson and Spours coined the term "political era” with three main dimensions.

The first is historical background, which can effectively shape the overall system of education. Historically, HK was once a British colony. Thus, English was the official language. Consequently, the influence of English on HK policy and political practices for more than 150 years was strong (Coniam \& Falvey, 2001; Lin, 2007). Owing to the prominent prerogatives of English, fluent utterance manifests the equivalence of high socio-economic status. The high standard of English became the threshold requirement for one to achieve the status of elites.

The second is societal changes. The salience and prestige of English did not become obsolete even after the handover of HK to the Chinese government in 1997. Instead, English shares an equally significant role as Chinese in the production of official documents, reports, statements, and relevant discourses. The majority of these texts are standardized to facilitate translation to both Chinese and English.

The third dimension refers to the dominant political ideology, which strongly influences the variables for reform. In this dimension, the prevalence of English remained a dominant political ideology even after the shift in the sovereignty. In some cases however, the intention of the government to move English from the frontline was evident in the effort to empower the Chinese language. For example, the adoption of Chinese as the Medium of Instruction (CMI) implied influence on the secondary school education system. Nevertheless, no developments indicated the removal of English as a priority, notwithstanding that bilingualism was considered as the highlighted developmental dimension advocated by the government. In essence, the government advocates that English, which is considered the global language, is the basic competence of a global citizen.

Conclusively, all the above factors, including socio-economic status, policy, culture, private sectors, and professional parties were in alignment as regards fast-tracking production of LPATE. As Hodgson and Spours suggest, the aforementioned three factors and education state form an equilibrium based on social and political foundations, which reflects the political ideology. Thus, the birth of LPATE could have been logically anticipated and perceived.

\section{Dimension 2. Education state}

The historical background draws upon the Hodgson and Spours second dimension, which is concerned with the 'education state', correlated with continuality of the political eras. The state does not simply consist of authority from the polity, governing body, and institution, but 
the roles of teachers, public, media, and significant figures as well.

In view of the significance of English, leading HK bureaucrats, particularly the Chief Executive of the Special Administrative Region (SAR), reemphasized the importance of English to upgrade HK as a cosmopolitan city such as New York or London (Berry \& McNeill, 2005). Thus, the Chief Executive designated the Education Bureau (EdB) and other advisory agents, such as ACTEQ, to figure out the feasibility of establishing a standard assessment, which can scrutinize the English proficiency of the frontline keepers of language education, i.e., the primary and secondary English teachers in HK.

The government agency ACTEQ was assigned to initiate consultation to investigate how LPATE could be implemented for secondary school English teachers. This move resulted in the establishment of the English Language Benchmark Subject Committee (ELBSC), which involved the members of ACTEQ, representatives from Examinations Authority (HKEA), school supervisors, senior teachers, student-teachers, tertiary language lecturers, and managers of relevant departments. The primary duties included working on the assessment formats, outlining the LPATE framework, customizing sample papers, and standardizing indicators, descriptors, and references over the assessment content as well as finalizing modifications of the assessment tools.

In consideration of the in-depth investigation, the ACTEQ requested the specialists Peter Falvey and David Coniam, from the Chinese University of Hong Kong (CUHK), to customize and develop the syllabus and curriculum of LPATE (Coniam \& Falvey, 2001). With the intention of establishing wider recognition through wider participation of teachers, they invited teachers' representatives to join the expertise group in validating the assessment methodologies and process.

During the consultation, various personnel and parties ranging from legislative councilors, education practitioners, and teachers alliance to business and commercials, academics, regional board, international schools, parents, and media, contributed their opinions in the production of the policy text.

In the LPATE case, the government adopted state-control in the entire practice in accordance with Roger (1997). The education sector and the government took for granted that that LPATE was state-controlled and state-run and as such, the government, which regulated all education policies and coordinated the central governance of LPATE, was the main employer of teachers. This argument was self-evident in the sense that all the consultations, proposals, and implementation were conducted by the government and its arms-length agencies. Nevertheless, the government neglected other sophisticated factors when responding to governance, such as the voices of dissent from teachers, which was later attributed to the grievance of teachers in the midst of LPATE implementation.

Dimension 3. Policy process

Drawing on the notion of Hodgson and Spours's third dimension, the policy process served as the spectacle that amplified the complexity of the moves and players involved in the policy process. The policy helped address the power distance, how the new ideologies enter the 
policy, and how policy interacts with practice.

Dimension 4. Political space

Hodgson and Spours' fourth dimension is concerned with the political space, which indicates the arena, or even the site of contestation. On this site, all stakeholders can counteract the policy process by engaging in ideological debate, which can result in compromise or further enhancement of the policy. Through investigation of various constraints and voices from different stakeholders from conception to actual implementation, appropriate solutions to the discrepancies can be determined.

Apparently, government consultation with teachers was inadequate in view of the top-down pressure exerted to fulfill the standard outlined in the examination (Ryan, 2008). Excessive emphasis on cohesion and compliance neglected the teachers' dilemmas and technical toughness, such as time, sophistication, and the resources deployed. Strictly speaking, the top-down management was proven to significantly undermine the capacity of teachers to counteract due to their dismay over the experience from LPATE.

Policy planning should allow a site of contestation where teachers and academics are allowed to voice out their opinions against the disorientated, unfair, and disadvantageous education policy. In this site, the role of teachers should be emphasized and they should be considered as group of policy makers because they can affect the interpretation of policy with different degrees of engagements. Otherwise, the teachers might act upon the undesired consequences of the policies as reflected during the LPATE implementation.

\section{Elaborations of the three contexts of Vidovich's checklist}

Based on the policy triangle (Bowe, et al., 1992) which indicates the three contexts, namely, 'the context of influence', 'the context of policy text production' as well as the 'context of practice', the policy development process of LPATE can be briefly construed based on the hints of Vidovich's checklist.

\subsection{Context of influence}

The context of influence can be deemed the congruent significance of English on HK due to its historic background and the emphasis people place on its salience. Vidovich (2000) furthered the significance by examining the context of influence in relation to examining a policy process. One of the questions is concerned with whether the international influences are in mediation with the policy. In this regard, LPATE could be considered to have been triggered by the competitiveness to strive for the entitlement as an international city advocated by the HK government and driven by the reputation of cosmopolitan cities such as London, New York, and Paris. To sustain global positioning, English standards undoubtedly comprise an influential factor. Additionally, possessing the history as British colony and the identity of Special Administrative Region (SAR) after 1997, the HK government aimed at nurturing trilingualism. Thus, Mandarin, Cantonese, and English are employed to foster global citizenship (Berry \& McNeill, 2005). Such political and ideological conditions 
catalyzed the production of LPATE. As previously mentioned, the most influential groups were the business sector, which complained about the low level of English competence; parents with high socio-economic status who were skeptical towards the unsatisfactory English standard of teachers; and educational practitioners who demanded professional development in English. Categorically speaking, the most influential interest group was the business sector, which was supported by evidence showing that HK Education Commission Report No.6 (ECR6) was mainly echoing the voices of this group.

\subsection{Context of policy text production}

In relation to the Bowe (1992) context of policy text production, the LPATE policy was not further consolidated prior to the production of the policy text ECR6 as published by the ACTEQ. In Vidovich's checklist, the policy text production primarily relates to its origins, construction process, interest groups involved, guiding values and rationale, key concepts, and accessibility and specifications of the implementation. The first concern is placed on the origin of the policy text. HK Education Commission Report No. 6 (ECR6), entitled 'Enhancing Language Proficiency: A Comprehensive Strategy' was published under the instigation of the working group designated by the Education Commission in October 1993 to address the impediments of refinement in language proficiency. The working group produced a report after a three-month public consultation, which started in July 1994. In view of the consistent propositions from the public, the commission opened up a space for a six-week consultation focused on the recommendation of English enhancement in December 1995. During the consultation, various personnel and parties including legislative councilors, education practitioners, business and commercials, academics, regional boards, international schools, parents, and media, contributed their opinions in the production of the policy text. When reviewing the processes to construct the policy text, the commission, in advance of the consultation, distributed to the above parties more than 40,000 copies of the draft report coupled with a pamphlet outlining the primary suggestions for further discussion. During the consultation, 20 briefing sessions were held among interested stakeholders. The compromises were thus made whilst the draft report aroused healthy public debates on the issue. Approximately 120 editorials and articles were submitted to major Chinese and English newspapers with 155 pieces of written feedback from educational communities, business unions, professional bodies, and the general public. Seemingly, concurrence on the underpinnings and recommendations was unanimous. The consensus from the stakeholders was because English proficiency was the common interest shared by the stakeholders. ECR 6 was categorized as an advisory report that offers recommendations to government for implementation. The discourse was generally persuasive because no imperatives could be found throughout the report.

At its root, the hidden agenda attributed to the ultimate outcome for this policy was to respond to the requirement in countenance to the stakeholders and to gain their confidence in the HK English standard. With deeper analysis, a common agreement was reached: the teachers lack the threshold English standard to deliver quality teaching in classrooms, particularly those who did not receive formal training and relevant language qualifications in the past. Therefore, the benchmark qualifications were proposed as a sustainable solution in 
overhauling the inadequacy with the displacement of the English teachers who could not meet the standard as a consideration.

The checklist of Vidovich (2002) focuses on the issues that influence the LPATE policy. One of the key issues was that the adoption of Chinese as MOI. Although widely accepted by teachers and education professionals, the general public particularly the parents attributed the decline of English to this policy. Consequently, the retrieval of English as MOI was put forward (DRAVE, 2010). This key issue focused the debate on whether the English language teachers have already attained the appropriate level of English. Therefore, the key concept of LPATE was based on the concord reached regarding these problems and their solutions, which pressured the commission to urge the government to provide the necessary resources to implement the report and to demonstrate its commitment to improve language proficiency in HK. Thus, the commission suggested to the Standing Committee on Language Education and Research (SCOLAR) to initiate research concerning the acquisition of English of students whose mother tongue is Chinese. In the conclusion of ECR 6, detailed phrases prescribing the steps for holistic implementation were demonstrated. The process began with building up the foundation in Phrase I and subsequently proceeded to accomplish the short-term goals in Phrase II and long-run operation of LPATE in Phrase III. Apparently, the ECR 6 report restated the significance of the effective deployment of labor and resources for smooth implementation of LPATE, which involved extra funding for the establishment of SCOLAR, research, employment of NET, intensive English Course, teachers' support, and public Education and Publicity Programmes. Thus, the financial implications were tangible in the policy text.

Briefly, the proposed solution was regarded as the benchmark assessment comprising five sets of papers on reading, listening, writing, speaking, and classroom language. Nonetheless, the exam results demonstrated the root weakness of the candidates, specifically in the advanced areas of English mechanics such as cohesive devices, predictive reading, integrated listening strategies, oral utterances, conversational skills, and explanation of grammatical mistakes in terms of linguistic terminology (Lin, 2007; Coniam \& Falvey, 2013). The solution also revealed that majority of the weak candidates, who were inadequate in English proficiency and subject knowledge, were mainly in-service teachers who had been teaching for a long time without acquiring the relevant degree and language teaching training. This observation highlighted the less restricted professional qualifications in the old days.

\subsection{Context of practice}

The context of practice refers to the struggles over policy practices and how the state overcomes the resistance from local education practitioners or other players within the interplay (Hodgson \& Spours, 2006). In this sense, the resistance to LPATE was collective. To in-service teachers, the failure in LPATE led to irreversible and unbearable consequences of losing the teaching posts, which posed an immeasurable threat to the failing teachers. Thus, intractability of the government implementation of the policy surfaced. As a result, LPATE encountered vigorous protests from teachers and initiated debates among the teachers' unions in early 2003 (Coniam \& Falvey, 2013). Aside from the overwhelming pressure to obtain the 
LPATE, spending a considerable amount of time on the LPATE relevant training became an added stress for teachers. The conflict and depression reached a climax when a few teachers committed suicide, which ultimately forced the government to readapt the overall implementation of LPATE to deter the possible adverse reactions from teachers and the public (Qian, 2008). Drawing on this notion, the teachers were not empowered by the policy, nor able to fulfill the requirement set by LPATE. The unintended consequences left the government with no choice but to amend largely the structures of the examinations. Thus, the most sophisticated parts, namely, the poem-reading section and the linguistic explanation of the grammar were replaced by selecting an option to explain the grammatical errors (Lin, 2007).

Simultaneously, the government allowed the teachers to obtain exemption by completing certain postgraduate courses (Berry \& McNeill, 2005). In short, the EDB document has indicated that those who obtained recognized degrees with English components integrated into study or practice, and relevant professional training, which included teacher training in specialized English and practice inside schools, could be exempted from the LPATE. For those whose degrees were not recognized could also complete a postgraduate program in subject knowledge to obtain the exemption. The most crucial amendment was the exemption for those who obtained teacher training before 2000, regardless of the training they received. The amendment highly reduced the pressure on the in-service teachers.

\subsection{Intentional and unintentional outcomes}

As mentioned previously, the original intention was an LPATE that was pragmatic, realistic, and responsive to the voices from the public. However, a decade has passed, but the outcomes of the LPATE remained inclined to be controversial in the sense that LPATE has been redirected from a standardized assessment to requirements a teacher should fulfill towards exemptions. Such moves can be rendered as a retreat or a regression on the aim to improve English. Thus, the pressure from possible bombardment from teachers would prevent the government to further the benchmark standards

Conversely, recent reports reveal that the number of teachers who have fulfilled LPATE has been increasing throughout the past six years. In response to the request of business to enhance English proficiency, the LPATE can be deemed comparatively satisfactory in the way with which it enhances teachers' English competence. Undoubtedly, as reflected by the gradual improvement of English teachers' standard, the government should be complimented on its effort to enhance English teaching quality.

In view of the enlightened intention underlying the LPATE and the significant progress achieved in betterment of the English standard of teachers, what can the education state, mainly the government, commit to respond to the request for betterment of English standard that can simultaneously manage the pressure from teachers? The writer would like to provide three recommendations, which might be insightful for researchers as they navigate the betterment process of the LPTAE policy. 


\subsection{Room for improvement}

First, the EdB, advisory board, and Examination Authority can critically evaluate the existing standard of LPATE to highlight the fact that the existing standard might be too high as well as the absence of adequate consideration with regard to how teachers under the category of LET might lack authentic English training. The second step is to revise the standard appropriately. The education state should not consider revising the syllabus or standard as a failure, but a temporal component during the implementation. As mentioned, policy text should always be adjustable to adapt to the ever-changing social and political contexts.

Second, the primary objectives corresponding to the request of business should be deemed unsuccessful owing to pressure and dismay that numerous teachers are experiencing. The situation leads to the ultimate failure of implementing the policy smoothly. Thus, except for the voices from business, EdB should actively widen its consultation spectrum by interacting frequently with teachers' unions, professional bodies, relevant researchers, and even individual teachers to create a multi-dimensional and comprehensive understanding as to what extent LPATE can become inclusive to all stakeholders.

Third, the seeming mismatch between output standard generated by the teacher training and the language proficiency required for the teaching profession in the past should be addressed. The current proficiency of these training programs are no longer relevant to the ever-changing environment in the transformation from skill-based to knowledge-based societal structure advocated by the HK government. Tertiary institutes should strengthen the language competence components of their pre-service and in-service education courses. In a wider scope, studies that investigate language proficiency needed for effective teaching should be encouraged in the light of their future contributions in adjusting the suitability of benchmarking and course content of the education programs.

Except for subject knowledge, language proficiency, and skills needed, tertiary institutes offering education courses can foster student-teachers' repertoire via a more holistic, comprehensive, and independent approach. Examples are the problem-solving and critical analysis skills, which help teachers reshape themselves to fit the evolving and competitive environment. In short, the ultimate aim is not just to change the teachers, but to transform them to survive. Research in this area can be widened to include policy makers' horizons in legitimatizing policies concerning teacher training and requirements.

\section{Conclusion}

Since the 1990s, stakeholders from the business and education sectors as well as from the general public focused on the deterioration of English as reflected by the declining examination results and unsatisfactory performance of employees. This scenario led to the production of LPATE, which affected approximately 12,500 English language teachers from the primary and secondary levels. Generally, however, teachers' voices are not heard in the process starting from conceptualization of the policy to the implementation process and evaluation. Seemingly, the teachers, who are the practitioners of LPATE, are authorized with 
the least power from the point wherein they perceive the new policy to its implementation. Nevertheless, the ultimate outcomes reflect the possibility that teachers can finally redirect the entire implementation and change government intentions. With the above recommendations, the pressure and the grievance of teachers might be alleviated and as a result, the LPATE might simultaneously be refined.

\section{References}

Berry, V., \& McNeill, A. (2005). Raising English language standards in Hong Kong. Language Policy, 4(4), 371-394.

Bowe, R. (1992). Reforming Education And Changing Schools: Case Studies In Policy Sociology Author: Richard Bowe, Publisher: Routledge Pag.

Coniam, D. (1994). Computer-Mediated Communication and Teacher Education: The Case of" Telenex.". In: Bird, Norman, Ed., And Others. Language and Learning. Papers presented at the Annual International Language in Education Conference (Hong Kong, 1993);

Coniam, D., \& Falvey, P. (2001). Awarding passes in the language proficiency assessment for teachers of English: Different methods, varying outcomes. EDUCATION JOURNAL-HONG KONG-CHINESE UNIVERSITY OF HONG KONG, 29(2), 23-36.

Coniam, D., \& Falvey, P. (2013). Ten years on: The Hong Kong Language Proficiency Assessment for Teachers of English (LPATE). Language Testing, 30(1), 147-155. http://dx.doi.org/10.1177/0265532212459485

Dale, R. (1997). The state and the governance of education: An analysis of the restructuring of the state-education relationship. Education, culture, economy and society, 273-282.

Drave, N. (2010). Keeping up Appearances: maintaining standards in Hong Kong's Language Proficiency Assessment for Teachers of English (LPATE). Paper presented at the 36th International Association for Education Assessment conference, Bangkok, Thailand.

Hodgson, A., \& Spours, K. (2006). An analytical framework for policy engagement: The contested case of 14-19 reform in England. Journal of Education Policy, 21(6), 679-696. http://dx.doi.org/10.1080/02680930600969233

Lin, A. M. (2007). English Language Proficiency Assessment for English Language Teachers in Hong Kong: Development and Dilemmas. Reading, 86(55), 63.

Qian, D. D. (2008). English language assessment in Hong Kong: A survey of practices, developments and issues. Language Testing, 25(1), 85-110. http://dx.doi.org/10.1177/0265532207083746

Ryan, N. (2008). Unravelling conceptual developments in implementation analysis. Australian Journal of Public Administration, 54(1), 65-80. 
http://dx.doi.org/10.1111/j.1467-8500.1995.tb01112.x

Vidovich, L. (2002). Expanding the toolbox for policy analysis: Some conceptual and practical approaches: Comparative Education Policy Research Unit, Department of Public and Social Administration, City University of Hong Kong.

\section{Websites}

HK Education Commission Report No.6 (ECR6)

http://www.edb.gov.hk/attachment/en/about-edb/publications-stat/major-reports/ecr6_e_2.pdf

Language Proficiency Assessment for Teachers, Hong Kong Examinations and

Assessment Authority

http://eant01.hkeaa.edu.hk/hkea/topper_otherexam.asp?p_coverdown=otherexam_3.html

Education Commission Reports

http://www.e-c.edu.hk/eng/online/on1.html

EDB - Recommendations of SCOLAR on Language Teacher Education and

Qualifications

http://www.edb.gov.hk/index.aspx?nodeid=685\&langno=1

\section{Copyright Disclaimer}

Copyright for this article is retained by the author(s), with first publication rights granted to the journal.

This is an open-access article distributed under the terms and conditions of the Creative Commons Attribution license (http://creativecommons.org/licenses/by/3.0/). 